\title{
The Carbohydrate-binding Specificity and Molecular Modelling of Canavalia maritima and Dioclea grandiflora Lectins
}

\author{
Márcio Viana Ramos/ ${ }^{+}$, Renato de Azevedo Moreira, José Tadeu Abreu \\ Oliveira, Benildo Sousa Cavada, Pierre Rougé*
}

\begin{abstract}
Laboratório de Lectinas, Departamento de Bioquímica e Biologia Molecular, Universidade Federal do Ceará, Caixa Postal 6020, 60451-970 Fortaleza, CE, Brasil *Laboratoire de Biologie Cellulaire, Faculté des Sciences Pharmaceutiques, 35 Chemin des Maraichers, 31062 Toulouse Cedex, France
\end{abstract}

The carbohydrate-binding specificity of lectins from the seeds of Canavalia maritima and Dioclea grandiflora was studied by hapten-inhibition of haemagglutination using various sugars and sugar derivatives as inhibitors, including $\mathrm{N}$-acetylneuraminic acid and $\mathrm{N}$-acetylmuramic acid. Despite some discrepancies, both lectins exhibited a very similar carbohydrate-binding specificity as previously reported for other lectins from Diocleinae (tribe Phaseoleae, sub-tribe Diocleinae). Accordingly, both lectins exhibited almost identical hydropathic profiles and their three-dimensional models built up from the atomic coordinates of ConA looked very similar. However, docking experiments of glucose and mannose in their monosaccharide-binding sites, by comparison with the ConA-mannose complex used as a model, revealed conformational changes in side chains of the amino acid residues involved in the binding of monosaccharides. These results fully agree with crystallographic data showing that binding of specific ligands to ConA requires conformational chances of its monosaccharide-binding site.

Key words: Canavalia maritima - carbohydrate-binding specificity - Diocleinae - Dioclea grandiflora - lectins molecular modelling

In recent years, lectins have become very attractive proteins due to their extensive use as probes for both the characterization and isolation of simple and complex sugars (Lis \& Sharon 1991) and as useful tools in immunological studies (Moreira et al. 1991). Accordingly, lectins are, by now, the plant proteins of best known three-dimensional structures. Following the pioneering works of Hardman and Ainsworth (1972) and Edelman et al. (1972) on the three-dimensional structure of ConA, the 3D-models of seven lectins have been solved at atomic resolution: PSA from pea (Einspahr et al. 1986); Favin from Vicia faba (Reeke \& Becker 1986); LoLI from Lathyrus ochrus (Bourne et al. 1990a); GSIV from Griffonia simplicifolia (Delbaere et al. 1990); EcoL from Erythrina corallodendron (Shaanan et al. 1991); PNA from peanut (Banerjee et al. 1993) and LCA from lentil (Loris et al. 1993). In addition, complexes of legume lectins with simple or more com-

This work was supported by Conselho Nacional de Desenvolvimento Científico e Tecnológico (CNPq) Brasil.

${ }^{+}$Corresponding author. Fax: +55-85-288.9829

Received 22 January 1996

Accepted 11 July 1996 plex sugars were solved by X-ray analysis: ConA with mannose (Derewenda et al. 1989); LoLI with glucose and mannose (Bourne et al. 1990b), with a trimannoside (Bourne et al. 1990c), with an octasaccharide (Bourne et al. 1992) of the $N$ acetyllactosaminic type and with Muramic (MurAc) and $\mathrm{N}$-acetylmuramic (MurNAc) acids (Bourne et al. 1994a); PSA with a trimannoside (Rini et al. 1993); GSIV with a tetrasaccharide of the Lewis ${ }^{b}$ group (Delbaere et al. 1993); LoLII with a glycoprotein (N2) derived from human lactotransferrin (Bourne et al. 1994b), and SBA from soybean with a biantennary analog of the blood group I antigen (Dessen et al. 1995). These complexes have shown that the monosaccharidebinding site of lectins plays a key role in the binding of either monosaccharides or more complex glycans. Along this way, a single monosaccharide unit of the complex glycan binds to the monosaccharide-binding site while other non covalent bonds occurring at the interface of both molecules, e.g. hydrogens bonds often mediated by water molecules and hydrophobic interactions, stabilize the complex between lectins and their ligands (Sharon 1993).

Diocleinae lectins have been recently demonstrated to act as strong inducers of lymphocyte proliferation and $\gamma$-interferon production (Barral-Netto 
method, were placed in boxes following the assignment of the $\alpha$-carbons coordinates from ConA to each segment. The segments of ConM primary sequence not determined were modelled by homology with other lectins from Canavalia genus which show $100 \%$ of identity in these regions. Docking experiments were carried out using the coordinates of the ConA- $\alpha$-methyl-mannopyranoside complex (Derewenda et al. 1989). Molecular modelling and docking were performed on a Silicon Graphics Personal Iris 4D25G workstation. As a result of the high identity among the primary sequences of the studied lectins, Ramachandran plots from ConM and DGL models were very similar to that of ConA structure. Only few bad contacts were identified between amino acids in the models. The bad distances were corrected by altering the dihedral angles involving side chain atoms.

\section{RESULTS}

The comparison of amino acid sequences of ConM and DGL to that of ConA showed a high degree of both identity and homology (Fig. 1). Accordingly, the hydropathic profiles (Fig. 2) and the HCA plots (results not shown) of all these Diocleinae lectins looked very similar, except for a few discrepancies. As a result, the molecular models of ConM and DGL built up from the coordinates of ConA strongly resembled that of ConA. Each monomer exhibited a flattened dome-shaped structure, the walls of which correspond to seven (front face) and six (back face) strands of antiparallel $\beta$ sheet interconnected by reverse turns and loops (Fig. 3). At the top of each monomer, a few convergent loops forming a small pocket constitute a monosaccharide-binding site responsible for the binding of simple sugars (mannose, glucose) to the lectins.

Both ConM and DGL similarly reacted with simple sugars and their derivatives, including $N$ acetylmuramic acid and $N$-acetylneuraminic acid (Table). However, few discrepancies occurred with some of the checked carbohydrates, i.e., raffinose, glucose and fructose.

Docking experiments performed with both mannose and glucose showed that the monosaccharide-binding sites of ConM and DGL are quite similar to that of ConA (Fig. 4). In this respect, a network of hydrogen bonds identical to that described for ConA (Derewenda et al. 1989) connects the sugar residues to the amino acids forming the monosaccharide-binding site. However, conformational changes in the side chain of some residues were observed (Fig. 5), which could explain some of the discrepancies reported in inhibition of haemagglutination (see Table).
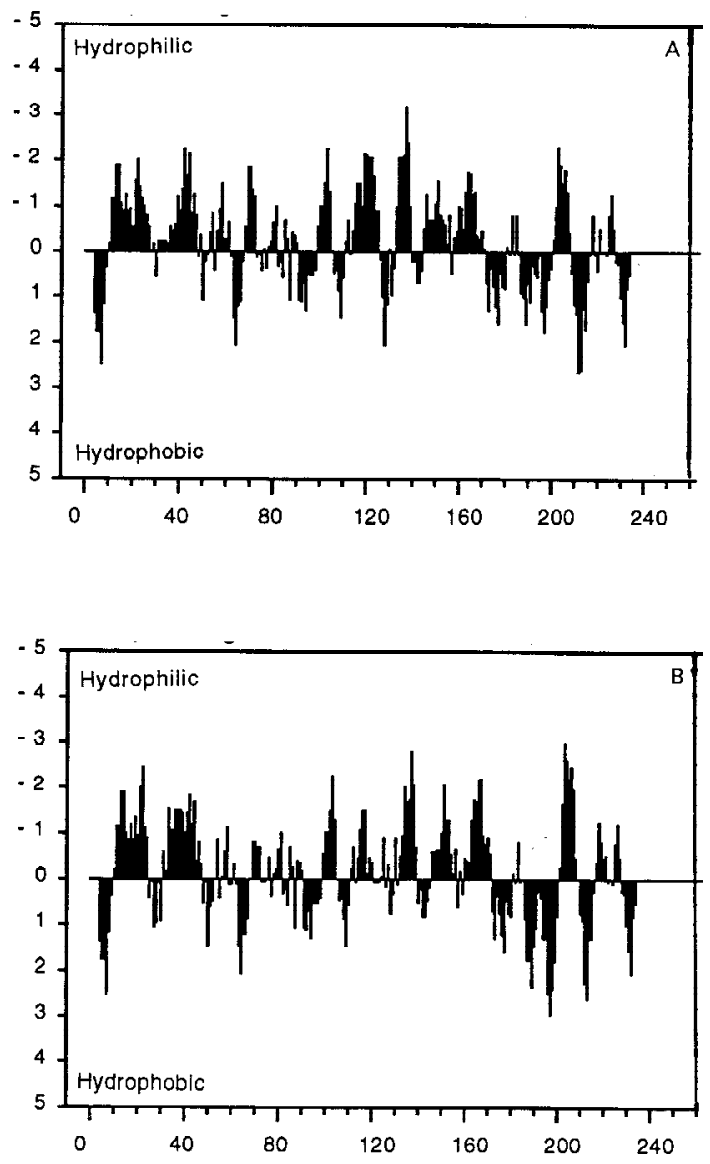

Fig. 2: comparison of the hydropathic profiles of Canavalia maritima (A) and Dioclea grandiflora (B) lectin plots according to Kyte and Doolittle (1982).
A

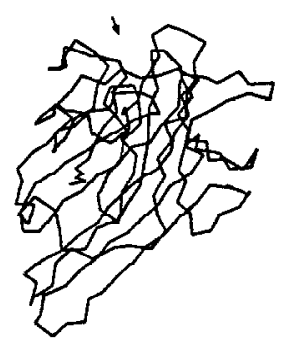

C

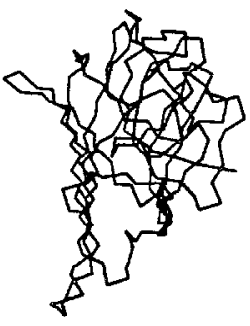

B

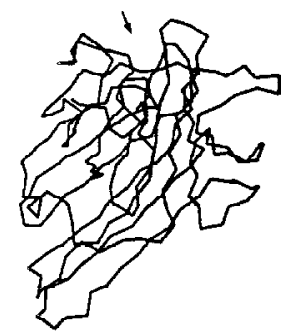

$\mathrm{D}$

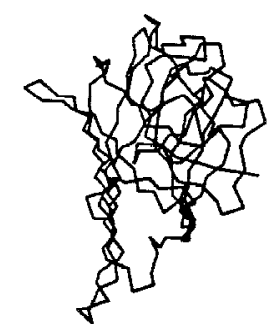

Fig. 3: three-dimensional models showing the front faces of Dioclea grandiflora (A) and Canavalia maritima (B) lectins and the side views of DGL (C) and ConM (D). The location of the monosaccharide-binding sites is indicated by arrows. 
A

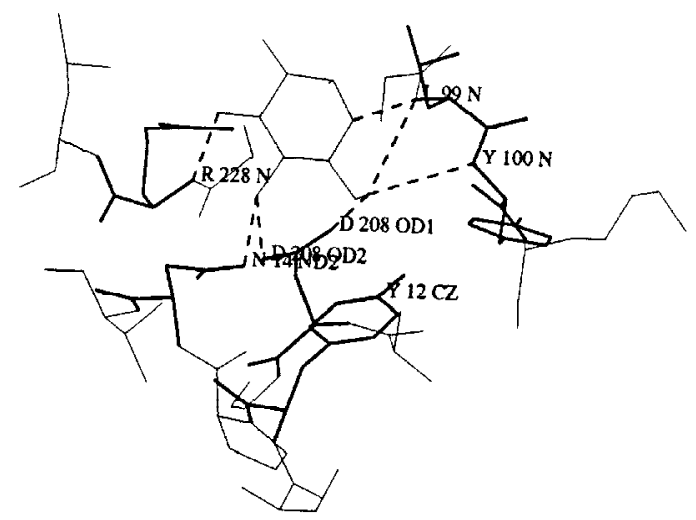

B

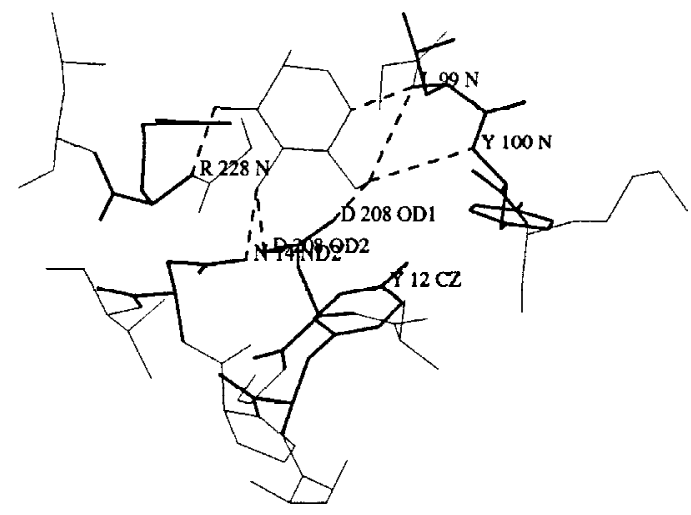

Fig. 4: molecular docking in the monosaccharide-binding site of the studied lectins (thick lines) with glucose (A) and mannose (B).

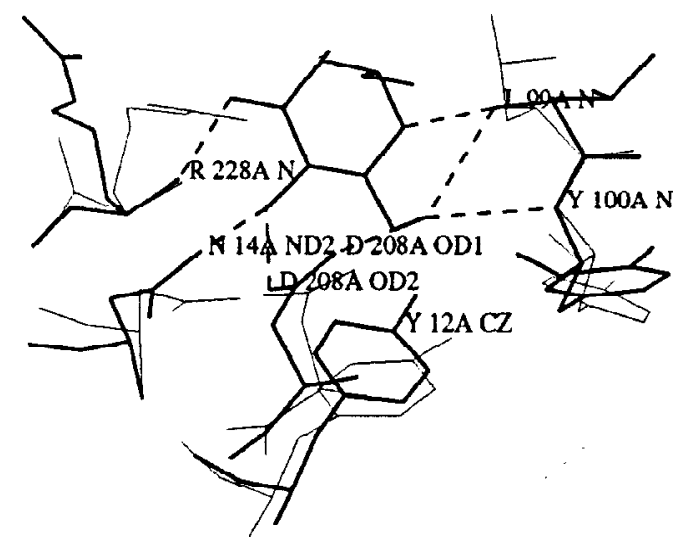

Fig. 5: superimposition of the monosaccharide-binding sites of Dioclea grandiflora (thin lines) and Canavalia ensiformis lectins complexed with $\alpha$-methyl-mannopyranoside (thick lines) showing the changes in side chain disposition in the complexed structure.
TABLE

Inhibition of the haemagglutinating activity of Canavalia maritima and Dioclea grandiflora lectins by sugars ${ }^{a}$

\begin{tabular}{|c|c|c|}
\hline \multirow[t]{2}{*}{ Sugars } & \multicolumn{2}{|c|}{ Lectins } \\
\hline & ConM & DGL \\
\hline$\beta$-D(-)fructose ${ }^{b}$ & 4.2 & 16.7 \\
\hline maltose ${ }^{b}$ & 1.0 & 4.2 \\
\hline $\mathrm{L}(-) \operatorname{sorbose}^{b}$ & 8.3 & 16.7 \\
\hline $\mathrm{D}(+)$ threalose $^{b}$ & 1.0 & 2.1 \\
\hline$\alpha-\mathrm{D}(+)$ mellibiose ${ }^{b}$ & 2.1 & 2.1 \\
\hline $\operatorname{sucrose}^{b}$ & 8.3 & 16.7 \\
\hline $\mathrm{D}(+)$ raffinose $\mathrm{e}^{b}$ & 16.7 & NI \\
\hline$N$-acetylmuramic acid ${ }^{c}$ & 4.2 & 4.2 \\
\hline$N$-acetylneuraminic $\operatorname{acid}^{C}$ & 8.3 & 8.3 \\
\hline$\alpha-\mathrm{D}(+)$ galactose $^{b}$ & NI & NI \\
\hline polygalacturonic acid ${ }^{d}$ & NI & NI \\
\hline$P$-nitrophenyl-6- $O-\beta-\mathrm{D}$ & & \\
\hline$(+)$ galactopyranoside $e^{e}$ & NI & NI \\
\hline$\alpha-\mathrm{D}(+) \operatorname{mannose}^{b}$ & 2.1 & 2.1 \\
\hline$\alpha-\mathrm{D}(+)$ glucose $\mathrm{e}^{b}$ & 4.2 & 16.7 \\
\hline
\end{tabular}

$a$ : minimal concentration required to inhibit 1 haemagglutination unit; NI: not inhibitory even at the following concentrations: $33.3 \mathrm{mM} b, 8.3 \mathrm{mM} c, 0.33 \% d$ and 3.3 $\mathrm{mM} e$.

\section{DISCUSSION}

Despite some changes occurring in the amino acid sequences of Diocleinae lectins, their threedimensional structures have been nicely conserved during evolution and strongly resemble those of other legume lectins (for review see Rougé et al. 1991). The structural similarities observed among Diocleinae lectins confirm these proteins as excellent phylogenetic markers as proposed by Moreira et al. (1995). The amino acid residues involved in the binding of monosaccharides $\left(\mathrm{Tyr}^{12}, \mathrm{Asn}^{14}\right.$, $\mathrm{Leu}^{99}$, Tyr ${ }^{100}, \mathrm{Asp}^{208}$ and $\mathrm{Arg}^{228}$ ) by ConA are completely conserved in other Diocleinae lectins. As a result, all these lectins exhibit a quite similar carbohydrate-binding specificity as shown by hapten-inhibition of haemagglutination by simple sugars and derivatives (Table). Their ability to bind $N$-acetylmuramic acid and $N$-acetylneuraminic acid, which has been reported for many legume lectins (Ayouba et al. 1991, 1992), is of special interest since these molecules are surface components of various saprophytic or pathogenic bacteria or fungi. Moreover, LoLI from Lathyrus ochrus seeds has been recently co-crystallized with both muramic acid and muramyl-dipeptides (Bourne et al. 1994a).

These results suggest that lectins could play similar biological roles possibly related with recognition processes occurring between plants and microorganisms. However, the analysis of carbo- 
hydrate-specificity of ConM and DGL towards mono-, di- and trisaccharides reveals some discrepancies, as previously shown for other lectins from the Diocleinae sub-tribe (Ayouba et al. 1993). Our molecular modelling studies confirm that the monosaccharide-binding sites of ConM and DGL are very similar to that of ConA. Similarly, our docking experiments performed with glucose and mannose show that a hydrogen bonding scheme similar to that observed in ConA (Derewenda et al. 1989) connects both sugars to the sites (Fig. 4). As shown in ConA-sugar complexes (Naismith et al. 1994), although the main chain positions of the amino acid residues forming the monosaccharidebinding site of ConA remain very similar in both complexed and native structures of ConA, their side chains are altered in the complexed form. Especially, $\mathrm{Leu}^{99}, \mathrm{Tyr}^{100}$ and $\mathrm{Arg}^{228}$ undergo drastic conformational changes upon binding to sugars. These findings suggest that suitable conformational changes occur in Diocleinae lectin binding-sites to make possible their interaction with monosaccharides. This monosaccharide-binding site flexibility observed for ConA, ConM and DGL could explain, at least in part, the overall ability of legume lectins to recognize distinct glycan structures. As far as our results of docking experiments are concerned, it is reasonable to speculate that the monosaccharide-binding site of Diocleinae lectins may be somehow particular for each one, thus generating slight discrepancies in the affinity of closely related lectins towards identical ligands as showed for raffinose, glucose and fructose (Table) and hence towards complex carbohydrate structures. In addition, preliminary results based on the fine interaction of Diocleinae lectins, measured by surface plasmon ressonance, showed that remarkable differences exist in the association of each lectin and a specific ligand.

\section{REFERENCES}

Ayouba A, Chatelain C, Rougé P 1991. Legume lectins interact with muramic acid and $N$-acetylmuramic acid. FEBS Lett 289: 102-104.

Ayouba A, Martin D, Rougé P 1992. Recognition of muramic acid and $N$-acetylmuramic acid by Leguminosae lectins: possible role in plant-bacteria interactions. FEMS Microbiol Lett 92: 41-46.

Ayouba A, Roques D, Cavada BS, Oliveira JTA, Moreira RA, Rougé P 1993. The carbohydrate-specificity of three lectins from the tribe Diocleae: Canavalia brasiliensis, Cratylia floribunda and Dioclea grandiflora, p. 51-57. In J Basu, M Kundu, P Chakrabarti (eds), Lectins, Biology, Biochemistry, Clinical Biochemistry, Vol 9, Wiley Eastern Ltd, India.

Barral-Netto M, Santos SB, Barral A, Moreira LIM, Santos CF, Moreira RA, Oliveira JTA, Cavada BS 1992. Human lymphocyte stimulation by legume lectins from the Diocleae tribe. Immunol Inves 21: 297-303.

Banerjee R, Mande SC, Ganesh V, Das K, Dhanaraj V, Mahanta SK, Suguna K, Surolia A, Vijayan M 1994. Crystal structure of peanut lectin, a protein with an unusual quaternary structure. Proc Natl Acad Sci USA 91: 227-231.

Bento CAM, Cavada BS, Oliveira JTA, Moreira RA, Barja-Fidalgo C 1993. Rat paw edema and leukocyte immigration induced by plant lectins. Agent Actions 38: 48-54.

Bourne Y, Aberael C, Cambillau C, Frey M, Rougé P, Fontecilla-Camps JC 1990a. X-ray crystal structure determination and refinement at 1.9 A resolution of isolectin I from the seeds of Lathyrus ochrus. J Mol Biol 214: 571-584.

Bourne Y, Ayouba A, Rougé P, Cambillau C 1994a. Interaction of a legume lectin with two components of the bacteria cell wall. A crystallographic study. $J$ Biol Chem 269: 9429-9435.

Bourne Y, Mazurier J, Legrand D, Rougé P, Montreuil J, Spik G, Cambillau C 1994b. Interaction of a legume lectin with the human lactotransferrin N2 fragment or with the isolated biantennary glycopeptide: role of the fucose moiety. Structure 2: 209-219.

Bourne Y, Rougé P, Cambillau C 1990c. X-ray structure of a $(\alpha-\operatorname{Man}(1-3) \beta-M a n(1-4) G I c N A c)$-lectin complex at $2.1 \mathrm{~A}$ resolution. The role of water in sugar-lectin interactions. J Biol Chem 265: 1816118165.

Bourne Y, Rougé P, Cambillau C 1992. X-ray structure of a biantennary octasaccharide-lectin complex refined at 2.3 A resolution. J Biol Chem 267: 197203.

Bourne Y, Roussel A, Frey M, Rougé P, FontecillaCamps JC, Cambillau C 1990b. Three-dimensional structures of complexes of Lathyrus ochrus isolectin I with glucose and mannose: fine specificity of the monosaccharide-binding site. Proteins 8: 365-376.

Delbaere LTJ, Vandonselaar M, Prasad L, Quail JW, Pearlstone JR, Carpenter MR, Smillie LB, Nikrad PV, Spoohr U, Lemieux RU 1990. Molecular recognition of a human blood group determinant by a plant lectin. Can J Chem 68: 1116-1121.

Delbaere LTJ, Vandonselaar M, Prasad L, Quail JW, Wilson KS, Dauter Z 1993. Structures of the lectin IV of Griffonia simplicifolia and its complex with the Lewis b human blood group determinant at 2.0 A resolution. $J$ Mol Biol 230: 950-965.

Derewenda Z, Yariv J, Helliwell JR, Kalb (Gilboa) AJ, Dodson EJ, Papiz MZ, Wan T, Campbell J 1989. The structure of the saccharide-binding site of concanavalin A. EMBO J 8: 2189-2193.

Dessen A, Gupta D, Sabesan S, Brewer CF, Sacchettini JC 1995. X-ray structure of the soybean agglutinin cross-linked with a biantennary analog of the blood group I carbohydrate antigen. Biochemistry 34: 4933-4942.

Edelman GM, Cunningham BA, Reeke Jr GN, Becker JW, Waxdal MJ, Wang JL 1972. The covalent and three-dimensional structure of concanavalin A. Proc Natl Acad Sci USA 69: 2580-2584. 
Einspahr H, Parks EH, Suguna K, Subramanian E, Suddath FL 1986. The crystal structure of pea lectin at 3.0 A resolution. J Biol Chem 261: 16518-16527.

Gaboriaud C, Bissery V, Benchetrit T, Mornon JP 1987. Hydrophobic cluster analysis: an efficient new way to compare and analyse amino acid sequences. FEBS 1(224): 149-155.

Hardman KD, Ainsworth CF 1972. Structure of concanavalin A at 2.4 A resolution. Biochemistry 11: 4910-4919.

Kyte J, Doolittle RF 1982. A simple method for displaying the hydrophobic character of a protein. $J$ Mol Biol 157: 105-132.

Lis H, Sharon N 1991. Lectin-carbohydrate interactions. Current Op Struct Biol 1: 741-749.

Loris R, Steyaert J, Maes D, Lisgarten J, Pickersgill R, Wyns L 1993. Crystal structure determination and refinement at $2.3 \mathrm{~A}$ resolution of the lentil lectin. Biochemistry 32: 8772-8781.

Moreira RA, Ainouz IL, Oliveira JTA, Cavada BS 1991. Plant lectins, chemical and biological aspects. Mem Inst Oswaldo Cruz 86 (Suppl. II): 211-218.

Moreira RA, Barros ACH, Stewart JC, Pusztai A 1983. Isolation and characterization of a lectin from the seeds of Dioclea grandiflora (Mart.). Planta 158: 63-69.

Moreira RA, Cordeiro EF, Cavada BS, Nunes EP, Fernandes AG, Fernandes AG, Oliveira JTA 1995. Lectins and the chemotaxonomy of the sub-tribe Diocleinae (Leguminosae - Phaseolae). R Bras Fisiol Veg 7: 7-14.
Naismith JH, Emmerich C, Habash J, Harrop SJ, Helliwell JR, Hunter WN, Raftery J, Kalb AJ (Gilboa), Yariv J 1994. Refined structure of concanavalin A complexed with methyl $\alpha$-Dmannopyranoside at 2.0 A resolution and comparison with the saccharide-free structure. Acta Cryst D50: $847-858$.

Reeke Jr GN, Becker JW 1986. Three-dimensional structure of favin: saccharide bindig-cyclic permutation in leguminous lectins. Science 234: 1108- 1111.

Rini JM, Hardman KD, Einspahr H, Suddath FL, Carver JP 1993. X-ray crystal structure of a pea lectintrimannoside complex at $2.6 \mathrm{~A}$ resolution. $J$ Biol Chem 268: 10126-10132.

Rodriguez D, Cavada BS, Oliveira JTA, Moreira RA, Russo M 1992. Differences in macrophage stimulation and leukocyte accumulation in response to intraperitoneal administration of glucose/mannosebinding plant lectins. Braz J Med Biol Res 25: 823826.

Rougé P, Cambillau C, Bourne Y 1991. The three-dimensional structure of legume lectins, p. 143-159. In DC Kilpatrick, E Van Driessche, TC Bog-Hansen (eds) Lectin Reviews Vol. 1, Sigma Chemicals Co., Saint-Louis, MO, USA.

Shaanan B, Lis H, Sharon N 1991. Structure of a legume lectin with an ordered $N$-linked carbohydrate in complex with lactose. Science 254: 862-866.

Sharon N 1993. Lectin-carbohydrate complexes of plants and animals: an atomic view. Trends Biochem Sci 18: 221-226. 